\title{
The Falling Weight Deflectometer: Application to Railway Substructure Evaluation
}

\author{
J. Fernandes ${ }^{1}$, A. Paixão ${ }^{2}$, S. Fontul ${ }^{2}$ and E. Fortunato ${ }^{2}$ \\ ${ }^{1}$ Faculty of Science and Technology, Universidade Nova de Lisboa, Portugal \\ ${ }^{2}$ Department of Transportation, National Laboratory for Civil Engineering, \\ Lisbon, Portugal
}

Keywords: non-destructive load test, falling weight deflectometer, bituminous sub-ballast, structural numerical modelling, dynamic load.

The increased speed of railway traffic results in an increase of the dynamic effect of the loads on the track structure. Therefore, for railway design and rehabilitation more realistic numerical models of the track structure are required. On the other hand, in order to evaluate the structure condition of existing tracks, in situ tests have to be performed. The non-destructive load tests, generally applied for pavement structural evaluation, can be adapted to railway structures and, in this way, can result in a more efficient monitoring of the track condition $[1,2]$.

A study has been developed with the aim of to exploring the application of the falling weight defelectometer (FWD) to railway structural analysis. In case of railways the dynamic effects on the loading are even more significant on the structural response.

In the case study presented in this paper, finite element models were developed using ANSYS. Two-dimensional axisymmetric and threedimensional structural models were analysed in order to study the influence of the dynamic nature of the FWD loading. It was found that modelling the action of the FWD could be performed more efficiently with a simplified two-dimensional model, which could provide quick and reliable results when compared with those obtained using the threedimensional model.

Regarding the numerical modelling of the dynamic load of the FWD, it was found that, in general, larger deflections were obtained when compared with the static scenario, so this type of analysis should not be neglected.

\section{References}

1 E. Fortunato, "Renovação de plataformas ferroviárias - Estudos relativos à capacidade de carga", PhD Thesis, Faculdade de Engenharia da Universidade do Porto, Portugal, 2005. (in Portuguese)

2 M. Burrow, A. Chan, A. Shein, "Deflectometer-based analysis of ballasted railway tracks", Proceedings of the Institution of Civil Engineers: Geotechnical Engineering, 160, 169-177, 2007. 